\title{
Analytical model for CFRP strengthened circular RC column under elevated temperature
}

\begin{abstract}
In order to increase the load carrying capacity and/or increase the service life of existing circular reinforced concrete bridge columns, Carbon Fiber Reinforced Polymer (CFRP) composites could be utilized. Transverse wrapping of circular concrete columns with CFRP sheets increases its axial and shear strengths. In addition, it provides good confinement to the concrete column core, which enhances the bending and compressive strength, as well as, ductility. Several experimental and analytical studies have been conducted on CFRP strengthened concrete cylinders/columns. However, there seem to be lack of thorough investigation of the effect of elevated temperatures on the response of CFRP strengthened circular concrete columns. A concrete confinement model that reflects the effects of elevated temperature on the mechanical properties of CFRP composites, and the efficiency of CFRP in strengthened concrete columns is presented. Tensile strength and modulus of CFRP under hot conditions and their effects on the concrete confinement are the primary parameters that were investigated. A modified concrete confinement model is developed and presented.
\end{abstract}

Keyword: CFRP; Circular concrete column; Confinement; Elevated temperature and humidity 